\title{
Modulatory Effects of Antibody Replacement Therapy to Innate and Adaptive Immune Cells
}

\author{
Isabella Quinti ${ }^{1 *}$ and Milica Mitrevski ${ }^{2}$ \\ 'Department of Molecular Medicine, Sapienza University of Rome, Rome, Italy, ${ }^{2}$ Department of Clinical Medicine, Sapienza \\ University of Rome, Rome, Italy
}

\section{OPEN ACCESS}

Edited by:

Antonio Condino-Neto, University of São Paulo, Brazil

Reviewed by: Mark Ballow, University at Buffalo, United States Siobhan Oisin Burns, University College London, United Kingdom Neil Romberg, Children's Hospital of Philadelphia, United States Alexandra Freeman, National Institutes of Health, United States

${ }^{*}$ Correspondence: Isabella Quinti isabella.quinti@uniroma1.it

Specialty section: This article was submitted to Primary Immunodeficiencies, a section of the journal Frontiers in Immunology

Received: 01 March 2017 Accepted: 29 May 2017 Published: 16 June 2017

Citation: Quinti I and Mitrevski M (2017) Modulatory Effects of Antibody Replacement Therapy to Innate and Adaptive Immune Cells.

Front. Immunol. 8:697. doi: 10.3389/fimmu.2017.00697
Intravenous immunoglobulin administered at replacement dosages modulates innate and adaptive immune cells in primary antibody deficiencies (PAD) in a different manner to what observed when high dosages are used or when their effect is analyzed by in vitro experimental conditions. The effects seem to be beneficial on innate cells in that dendritic cells maturate, pro-inflammatory monocytes decrease, and neutrophil function is preserved. The effects are less clear on adaptive immune cells. IVlg induced a transient increase of Treg and a long-term increase of CD4 cells. More complex and less understood is the interplay of IVIg with defective B cells of PAD patients. The paucity of data underlies the need of more studies on patients with PAD before drawing conclusions on the in vivo mechanisms of action of IVlg based on in vitro investigations.

Keywords: common variable immune disorders, X-linked agammaglobulinemia, IVIg replacement, innate immunity, adaptive immunity, in vivo

\section{INTRODUCTION}

Polyvalent intravenous immunoglobulin (IVIg) are used as replacement therapy in patients with primary antibody deficiencies (PAD), a group of defects characterized by a failure to mount protective antibody responses, including X-linked agammaglobulinemia (XLA) and common variable immune disorders (CVID), and as immunomodulatory treatment with high IVIg doses in patients with inflammatory-autoimmune diseases. IVIg contain a broad spectrum of antibody specificities against microorganism antigens able to opsonize and neutralize microbes and toxins. IVIg also contain functionally relevant natural autoantibodies toward a wide range of self-motifs such as Siglec 9 , Fas, and BAFF, together with a wide range of specificities including idiotypes of immunoglobulins, $\mathrm{T}$ cell receptor, HLA molecules, and other cell surface molecules of immunological importance such as CD4, CD5, BAFF, Fas, cytokines, cytokine receptors, and chemokine receptors that may participate in regulation of the immune response (1).

There are many reports on the various immunological effects of high-dose IVIg treatment in patients with inflammatory diseases. Clearly, the significantly smaller doses of immunoglobulin prescribed to PAD patients for replacement therapy may convey different effects (2). The possible immunomodulatory effect of IVIg administered at replacement dosages on innate and adaptive immune cells in patients with PAD needs to be addressed by detailed studies since the peak plasma IgG level reached in patients on replacement administration is much lower that the peak reached in patients with autoimmune-inflammatory disorders. Moreover, in vitro studies might not be a suitable system to replicate the in vivo effects of IVIg. In fact, it is possible that the in vitro effects of IVIg do not recapitulate the in vivo effects since many cellular and mediator interactions are lacking when 
IVIg are added in vitro to experimental conditions. Moreover, in vivo studies might help to analyze the immunomodulatory short- and long-term effects of immunoglobulin on immune cells and the beneficial effects due to the reduction of the infectionassociated immune activation that is likely to occur as a result of immunoglobulin replacement.

Several theories have been postulated about the mechanisms through which IVIg preparations exert their immune-regulatory properties at replacement dosages possibly involving different type of cells acting in concert (3). Moreover, the diversity of CVID immunological and clinical phenotype could affect the results of some of the experiments. In addition, the commercial IVIg preparation used to study the in vivo or in vitro effect should be considered, in that IVIg consist mainly of monomeric IgG, but if a residual amount of dimers is present in the preparation, the biological effects might be different (4).

\section{POLYMORPHONUCLEAR NEUTROPHILS (PMN)}

In response to pathogens, PMN rapidly migrate to the site of inflammation, release proteolytic enzymes and antimicrobial peptides as well as reactive oxygen species. IVIg might modulate PMN activity by a saturating and an activating/inhibiting effect on PMN FcyRs (5). Almost 20 years ago, the first demonstration that IVIg administered at low dosages in patients affected by PAD did not alter neutrophils functions was published (6). Phagocytosis, intracellular bactericidal activity, and chemotaxis of PMN in PAD patients treated at very low dosages (IVIg $200 \mathrm{mg} / \mathrm{kg} / \mathrm{month}$ ) and at replacement dosages (IVIg $600 \mathrm{mg} /$ $\mathrm{kg} /$ month) were comparable to those of healthy controls (6). We have recently confirmed these data showing that in CVID and XLA patients, PMN were capable in vivo to perform efficient migration, degranulation, phagocytosis, and oxidative burst at baseline and shortly after IVIg administration $(7,8)$. Moreover, IVIg infusion-administered in vivo at replacement dosages did not alter the PMN expression of receptors involved in PMN functions, such as CD181, CD66b, CD11b, CD11c, CD16, and Siglec $9(7,8)$.

In contrast with the in vivo data obtained from CVID and XLA patients infused with IVIg, experiments performed with IVIg added in vitro on isolated PMN or to whole blood (9) showed that IVIg (1-25 mg/ml) might affect the overall activity of PMN by (1) inducing apoptosis; (2) decreasing the pro-inflammatory activity; (3) inhibiting or activating PMN degranulation (10-15) (Figure 1).

Thus, in vitro experiments provided conflicting results of immunomodulatory effects on PMN activity depending on the concentration of IVIg added in vitro, while in vivo data showed that PMN remained fully functional in patients treated with replacement IVIg dosages (Figure 1).

\section{MONOCYTES}

Monocytes are now classified according to their expression of CD14, the receptor of LPS, and CD16, a low affinity Fcy receptor, into three different subsets: classical monocytes, non-classical monocytes, and intermediate monocytes also called pro-inflammatory monocytes based on gene expression profiling and cytokine production, such as TNF- $\alpha$, IL-1 $\beta$, and IL- $6(16,17)$. We have recently shown that CVID and XLA patients displayed an increased frequency of $\mathrm{CD} 14^{\text {bright }} \mathrm{CD} 16^{+}$pro-inflammatory intermediate monocytes $(8,18)$. In CVID and XLA patients, shortly after IVIg infusion, we observed a transient reduction of about one-fourth of peripheral monocytes, a decrease involving mainly pro-inflammatory intermediate monocytes. These data are in agreement with other observations showing that IVIg infusion induced a transient decrease in the number of pro-inflammatory monocytes that returned at baseline levels after $20 \mathrm{~h}$ and suppressed the production of pro-inflammatory cytokines (19). These phenomena might be an additional mechanism through which IVIg infusion exert an anti-inflammatory effect, even when infused at replacement dosages. It is possible that an apoptotic process is involved. In fact, IVIg preparations contain agonistic and antagonistic anti-CD95 antibodies interacting with $\mathrm{CD} 16^{+}$ monocytes that constitutively upregulated proapoptotic genes (20). Thus, these naturally occurring autoantibodies might contribute to the anti-inflammatory effects of IVIg via cell death regulation. In CVID and XLA shortly after IVIg infusion, we also observed a reduction of expression of functional monocyte receptors such as $\mathrm{CD} 11 \mathrm{~b}$ and Siglec 9 on classical monocytes associated, as expected, with a slight reduction of phagocytosis and oxidative burst functions that even if decreased remained in the normal range $(8,18)$. As described for anti-CD95, the reduction of Siglec 9 receptor might also be related to the binding of anti-Siglec 9 antibodies contained in IVIg preparations (20). It is then possible that IVIg bind to the Fc receptors on monocytes' surface and transiently limit the availability to bind opsonized bacteria.

In conclusion as shown in Figure 1, taken together our results showed that in XLA and CVID patients IVIg exert in vivo a short-term anti-inflammatory effect and do not severely affect the monocytes ability to appropriately respond to pathogens (8).

\section{DENDRITIC CELLS}

Dendritic cells are professional antigen-presenting cells essential for priming immune response. When immature, DC capture antigen efficiently, but only mature DC are potent T-cell activators. Maturation process modifies the expression of MHC molecules, co-stimulatory molecules and cytokines. $\mathrm{CD} 1$ proteins are $\mathrm{MHC}$ I-like markers of differentiation of DC. The groups 1 (CD1a, CD1b, and CD1c) and 2 (CD1d) are involved in lipid antigen presentation to the T cells (21). There are diverse subsets of DC: monocyte-related DC, blood myeloid (mDC), and plasmacytoid DC (pDC), precursors of tissue and lymphoid DC (22). In the presence of GM-CSF and IL-4, it is possible to induce the production in vitro of monocyte-derived DC (MdDC) $(23,24)$. Different subsets of DC express distinct CD1 profiles, suggesting that microenvironment could regulate diverse antigen presentation pathways.

Common variable immune disorder patients have a reduction of both pDC and mDC subsets (25). Their MdDC display disturbed differentiation, maturation, and function (24). In vitro and 


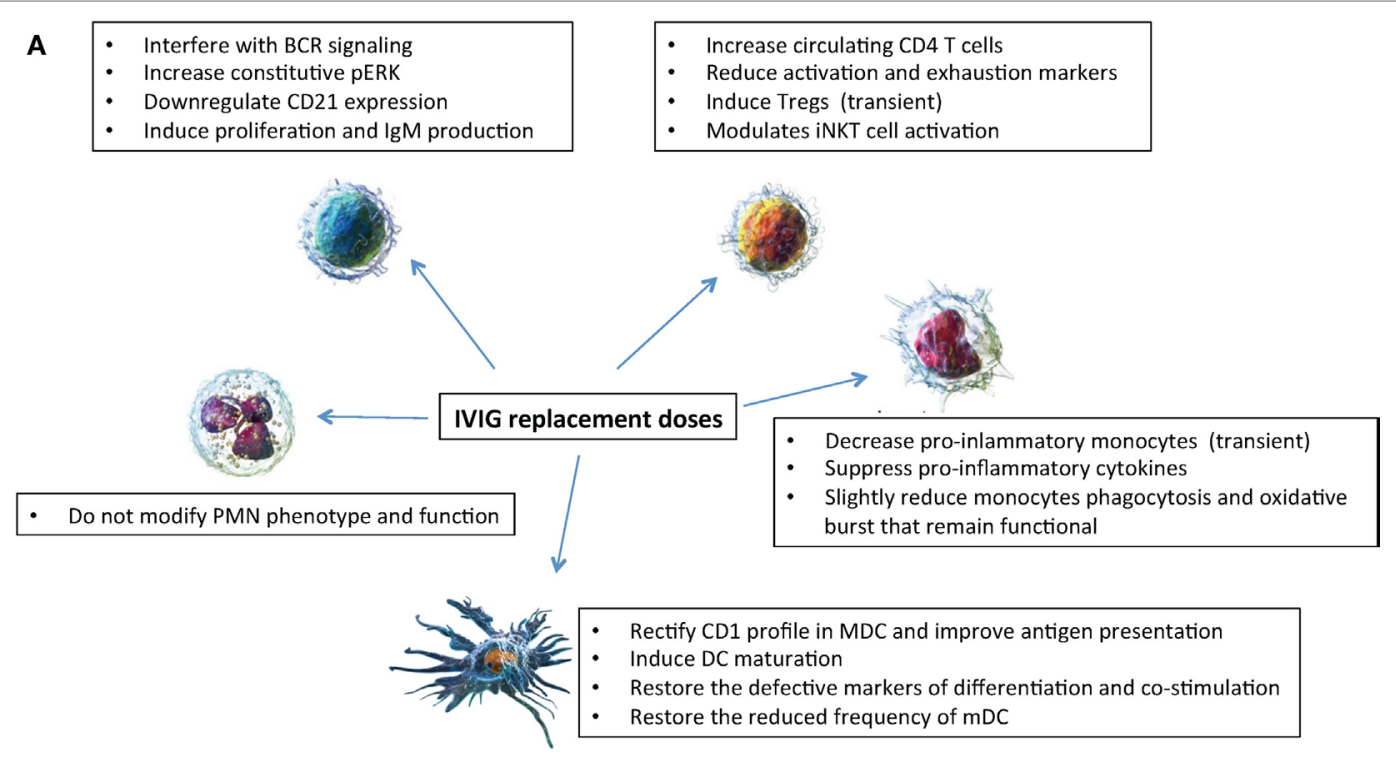

B

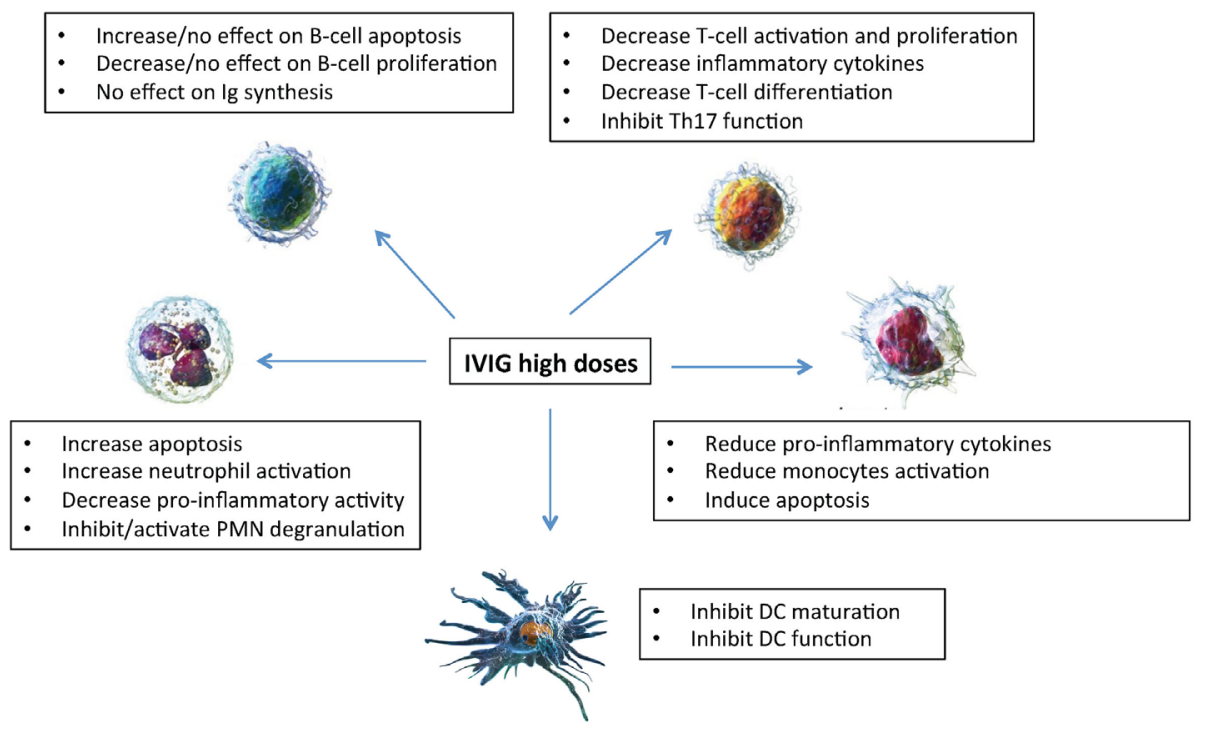

FIGURE 1 | Mechanisms of action of intravenous immunoglobulin (IVIg) on innate (neutrophils, monocytes, and dendritic cells) and adaptive (B and T lymphocytes) immune cells. Effects of IVIg (replacement dosages) (A); effects of IVlg (high dosages) (B). Cell images from Ref. (55).

in vivo experiments showed similar effects of IVIg on DC: the addition in vitro of IVIg at a concentration of $10 \mathrm{mg} / \mathrm{ml}$ to DC cultures of CVID patients partially restored the defective markers of differentiation (CD1a) and co-stimulation (CD80, CD86, and CD40) (26); a recent in vivo study in CVID demonstrated that after 6-12 months from initiation of replacement, IVIg therapy partially restored the reduced frequency of $\mathrm{mDC}$, the altered expression of their co-stimulatory molecules and the CD4 T cell count (27).

Moreover, in vitro studies showed that different concentrations of IVIg added to MdDC influenced the expression pattern of CD1 molecules (28); similarly, in vivo studies found that IVIg therapy normalized the elevated levels of CD1a and CD1b on mDCs of CVID patients (29). By regulating CD1 expression pattern on
DC, IVIg treatment affects the balance between CD1d-restricted antigen presentation to iNKT cells and group $1 \mathrm{CD} 1$-restricted antigen presentation to $\mathrm{T}$ cells (28). Thus, by fine tuning of the CD1 antigen presentation pathways, IVIg could provide suitable activation signals to the immune system.

Also XLA patients have reduced DC myeloid subset (25). Moreover, it was suggested that their DC failed to differentiate and to mature because of a hypogammaglobulinemic environment (30). These abnormalities were partially restored by adding IVIg in vitro during the differentiation of DC from monocytes. Natural CD40 reactive antibodies are likely to exert this effect through an agonistic action on CD40 (30).

Taken together, as shown in Figure 1, IVIg at replacement dosages has a number of beneficial effects on DC differentiation and 
function as demonstrated by in vivo and in vitro studies, which are different from the effects of IVIg $(0.15 \mathrm{mM})$ administered at high dosages that inhibited maturation and function of DC (24).

\section{B CELLS}

The B cell compartment is variably disturbed in patients with CVID. The total number of peripheral $\mathrm{B}$ cells is reduced in about $40-50 \%$ patients $(31,32)$. Class-switched memory B cells are reduced in $80-90 \%$ of CVID patients (31) often in association with defects of B cell receptor (BCR) activation (33) as well as the TLRs (34).

Therapeutic immunoglobulins interplay with B cells both directly, with surface receptors or intracellular molecules, and indirectly, influencing cytokines, survival factors or through other immune cells (35). Nevertheless, there is a shortage of studies that could unveil the effects of IVIg on B lymphocytes, particularly when administered at replacement dosages.

In vitro studies provided conflicting results. Graded concentration of IVIg (from low dose to high dose) demonstrated that IVIg did not affect the proliferative capacity of B cells, did not cause significant apoptosis of B cells, neither affected mRNA synthesis of both IgM and IgG (36). Other in vitro studies showed that IVIg at high dose $(0.15 \mathrm{mM})$ can directly inhibit B cell activation and proliferation (37) and can induce apoptosis in B lymphocytes by inducing a functional silencing program similar to anergy $(38,39)$ (Figure 1).

A recent study demonstrated that upon stimulation with physiological IVIg concentration added in vitro to experimental conditions, B cells from CVID patients were capable to proliferate and produce IgM (40). The authors suggested that antibodies within IVIg preparations rectified the defective signaling of $\mathrm{B}$ cells provided by $\mathrm{T}$ cells and delivered $\mathrm{T}$-independent signals. We confirmed a signal dysregulation intrinsic to B cells in a subgroup of CVID patients. CVID patients with expanded CD21low $B$ cells have high constitutive ERK activation [BCR signaling pathway important for B cell anergy (41)], low responsiveness to TLR9 and BCR stimuli, defective calcium signaling $(42,43)$, and propensity to apoptosis. IVIg infusion administered in vivo transiently increased constitutive $\mathrm{pERK}$, reduced the pERK increment induced by BCR cross-linking (44), and drove B cells to downregulate CD21 expression (45).

Thus, data on IVIg and B cells remained unclear and need to be elucidated. Moreover, the long-term consequences of IVIg on $\mathrm{B}$ cells of $\mathrm{PAD}$ patients have never been addressed due to the complex relationship between IgG and a number of factors that might contribute to the diverse $B$ cell abnormalities observed over time in heterogeneous disorders like CVID.

\section{T CELLS}

A relative loss of T-cell function in many CVID patients has been widely demonstrated, including low circulating CD4 T cells, low naive CD4 T cells, low antigen-specific T cells, impaired proliferation, activation, and secretion of cytokines (46). Many CVID patients present a persistent low CD4 T cell count. For the group of CVID patients with persistently low CD4 counts, it has been suggested to change the PID classification from CVID to late-onset combined immune deficiency (47).

An elegant study addressed the modulation of T cells in CVID patients treated with IVIG on a long-term basis. Following IVIg initiation, CD4 counts increase in the majority of CVID patients and can reach normal levels in some cases (48). IVIg reduced the expression of activation and exhaustion markers on CD4 and CD8 T cells, which might remain elevated for up to 1 year from IVIg treatment initiation. This suggests that IgG replacement control with time infection-associated factors implicated in $\mathrm{T}$ cell chronic activation (27). The authors concluded that an early initiation of IgG replacement therapy in CVID patients may be beneficial to prevent $\mathrm{T}$ cell activation by switching off the inflammatory status. The same effect was demonstrated in in vitro studies when IVIg were added to cultures even at physiological concentrations (49).

In CVID patients, Tregs frequency (50) and function have been shown to be reduced, and this defect might have a role in the pathogenesis of CVID-associated autoimmune or inflammatory complications. IVIg administration modulates Tregs as demonstrated by the transient increase in Tregs $30 \mathrm{~min}$ after IVIg infusion (51). However, no sustained effect on Treg frequency was observed, and thus additional studies are needed to address the in vivo long-term effect on Treg and the clinical impact of this finding.

In addition, CVID patients show a reduction of iNKT cells (52), a subset that control bacterial and viral infections by recognizing endogenous and bacterial-derived glycolipids presented by CD1d molecules. In CVID, iNKT cells showed an elevated expression of markers of activation and exhaustion such as HLA-DR, CD161, and PD-1. IVIg treatment did not improve the frequency of iNKT cells but reduced CD161and PD-1 expression and possibly reduced iNKT cell activation and exhaustion (27).

As shown in Figure 1, these effects differ from the data obtained in vitro when higher IVIg concentrations $(0.15 \mathrm{mmol} / \mathrm{L})$ were added to experimental conditions showing suppression of $\mathrm{T}$ cell proliferation (53), of amplification of human Th17 cells (54) and of multiple key effector/inflammatory cytokines (49). Taken together, IVIg at replacement dosages have a beneficial short-lived effect on Tregs and a beneficial long-term effect on $\mathrm{T}$ cells and possibly on iNKT cells.

\section{CONCLUSION}

IVIg administered at replacement dosages modulate innate and adaptive immune cells in PAD (Figure 1) differently to what observed when the effects of high dosages are evaluated. The effects seem to be beneficial on innate cells in that dendritic cells maturate, pro-inflammatory monocytes decrease, and neutrophil function is preserved. The effects are less clear on adaptive immune cells where a transient increase of Treg and a long-term increase of CD4 were demonstrated. More complex and less understood is the interplay of IVIg with defective B cells of PAD patients. The paucity of data underlies the need of more studies before drawing conclusions on the in vivo mechanisms of action of IVIg based on in vitro investigations. Moreover, should be noted that all studies presented refer to IVIg only and no data 
are available on in vivo studies of subcutaneous administration. Moreover, studies on SCIg might help to discriminate between short-term effect of IVIg administration due to the IgG peak reached at the time of the infusion and long-term effect due a constant IgG replacement.

\section{REFERENCES}

1. Farrugia A, Quinti I. Manufacture of immunoglobulin products for patients with primary antibody deficiencies - the effect of processing conditions on product safety and efficacy. Front Immunol (2014) 5:665. doi:10.3389/ fimmu.2014.00665

2. Kerr J, Quinti I, Eibl M, Chapel H, Späth PJ, Sewell WA, et al. Is dosing of therapeutic immunoglobulins optimal? A review of a three-decade long debate in Europe. Front Immunol (2014) 5:629. doi:10.3389/fimmu.2014.00629

3. Kaveri SV, Maddur MS, Hegde P, Lacroix-Desmazes S, Bayry J. Intravenous immunoglobulins in immunodeficiencies: more than mere replacement therapy. Clin Exp Immunol (2011) 164(Suppl 2):2-5. doi:10.1111/j.13652249.2011.04387.x

4. Durandy A, Kaveri SV, Kuijpers TW, Basta M, Miescher S, Ravetch JV, et al. Intravenous immunoglobulins - understanding properties and mechanisms. Clin Exp Immunol (2009) 158(Suppl 1):2-13. doi:10.1111/j.13652249.2009.04022.x

5. Nagelkerke SQ, Kuijpers TW. Immunomodulation by IVIg and the role of Fc gamma receptors: classic mechanisms of action after all? Front Immunol (2015) 5:674. doi:10.3389/fimmu.2014.00674

6. Van T, Sussman G, Pruzanski W. Impact of intravenous infusions of low and high doses of gamma globulins (IVIG) on phagocytic functions in adults with primary humoral immunodeficiency. Inflammation (1994) 18(4):419-26. doi:10.1007/BF01534439

7. Prezzo A, Cavaliere FM, Bilotta C, Iacobini M, Quinti I. Intravenous immunoglobulin replacement treatment does not alter polymorphonuclear leukocytes function and surface receptors expression in patients with common variable immunodeficiency. Cell Immunol (2016) 306-307:25-34. doi:10.1016/j. cellimm.2016.05.006

8. Cavaliere FM, Prezzo A, Bilotta C, Iacobini M, Quinti I. The lack of BTK does not impair monocytes and polymorphonuclear cells functions in X-linked agammaglobulinemia under treatment with intravenous immunoglobulin replacement. PLoS One (2017) 12(4):e0175961. doi:10.1371/journal. pone. 0175961

9. Casulli S, Topçu S, Fattoum L, von Gunten S, Simon HU, Teillaud JL, et al. A differential concentration-dependent effect of IVIg on neutrophil functions: relevance for anti-microbial and anti-inflammatory mechanisms. PLoS One (2011) 6(10):e26469. doi:10.1371/journal.pone.0026469

10. Aschermann S, Lux A, Baerenwaldt A, Biburger M, Nimmerjahn F. The other side of immunoglobulin G: suppressor of inflammation. Clin Exp Immunol (2010) 160(2):161-7. doi:10.1111/j.1365-2249.2009.04081.x

11. van Mirre E, Teeling JL, van der Meer JW, Bleeker WK, Hack CE. Monomeric IgG in intravenous Ig preparations is a functional antagonist of FcgammaRII and FcgammaRIIIb. J Immunol (2004) 173(1):332-9. doi:10.4049/jimmunol. 173.1.332

12. von Gunten S, Schaub A, Vogel M, Stadler BM, Miescher S, Simon HU. Immunologic and functional evidence for anti-Siglec-9 autoantibodies in intravenous immunoglobulin preparations. Blood (2006) 108(13):4255-9. doi:10.1182/blood-2006-05-021568

13. Pallister I, Bhatia R, Katpalli G, Allison D, Parker C, Topley N. Alteration of polymorphonuclear neutrophil surface receptor expression and migratory activity after isolation: comparison of whole blood and isolated PMN preparations from normal and post fracture trauma patients. J Trauma (2006) 60(4):844-50. doi:10.1097/01.ta.0000215583.08765.ce

14. François S, El Benna J, Dang PM, Pedruzzi E, Gougerot-Pocidalo MA, Elbim C. Inhibition of neutrophil apoptosis by TLR agonists in whole blood: involvement of the phosphoinositide 3-kinase/Akt and NF-kB signaling pathways, leading to increased levels of Mcl-1, Al, and phosphorylated Bad. J Immunol (2005) 174(6):3633-42. doi:10.4049/jimmunol.174.6.3633

\section{AUTHOR CONTRIBUTIONS}

IQ and MM contributed to this paper by designing the perspective, by contributing with experimental data, by analyzing the data in the literature, and by writing the manuscript.

15. Casulli S, Coignard-Biehler H, Amazzough K, Shoai-Tehrani M, Bayry J, Mahlaoui N, et al. Defective functions of polymorphonuclear neutrophils in patients with common variable immunodeficiency. Immunol Res (2014) 60(1):69-76. doi:10.1007/s12026-014-8555-7

16. Ziegler-Heitbrock L. Blood monocytes and their subsets: established features and open questions. Front Immunol (2015) 6:423. doi:10.3389/ fimmu.2015.00423

17. Wong KL, Tai JJ, Wong WC, Han H, Sem X, Yeap WH, et al. Gene expression profiling reveals the defining features of the classical, intermediate, and nonclassical human monocyte subsets. Blood (2011) 118(5):e16-31. doi:10.1182/ blood-2010-12-326355

18. Cavaliere FM, Prezzo A, Conti V, Bilotta C, Pulvirenti F, Iacobini M, et al. Intravenous immunoglobulin replacement induces an in vivo reduction of inflammatory monocytes and retains the monocyte ability to respond to bacterial stimulation in patients with common variable immunodeficiencies. Int Immunopharmacol (2015) 28(1):596-603. doi:10.1016/j.intimp.2015.07.017

19. Siedlar M, Strach M, Bukowska-Strakova K, Lenart M, Szaflarska A, Węglarczyk K, et al. Preparations of intravenous immunoglobulins diminish the number and proinflammatory response of CD14+CD16++ monocytes in common variable immunodeficiency (CVID) patients. Clin Immunol (2011) 139(2):122-32. doi:10.1016/j.clim.2011.01.002

20. von Gunten S, Simon HU. Cell death modulation by intravenous immunoglobulin. J Clin Immunol (2010) 30(Suppl 1):S24-30. doi:10.1007/s10875010-9411-8

21. Barral DC, Brenner MB. CD1 antigen presentation: how it works. Nat Rev Immunol (2007) 7:929-41. doi:10.1038/nri2191

22. Collin M, McGovern N, Haniffa M. Human dendritic cell subsets. Immunology (2013) 140(1):22-30. doi:10.1111/imm.12117

23. Sallusto F, Lanzavecchia A. Efficient presentation of soluble antigen by cultured human dendritic cells is maintained by granulocyte/macrophage colonystimulating factor plus interleukin 4 and downregulated by tumor necrosis factor alpha. J Exp Med (1994) 179(4):1109-18. doi:10.1084/jem.179.4.1109

24. Bayry J, Lacroix-Desmazes S, Carbonneil C, Misra N, Donkova V, Pashov A, et al. Inhibition of maturation and function of dendritic cells by intravenous immunoglobulin. Blood (2003) 101(2):758-65. doi:10.1182/ blood-2002-05-1447

25. Yong PF, Workman S, Wahid F, Exley A, Webster AD, Ibrahim MA. Selective deficits in blood dendritic cell subsets in common variable immunodeficiency and X-linked agammaglobulinaemia but not specific polysaccharide antibody deficiency. Clin Immunol (2008) 127(1):34-42. doi:10.1016/j.clim.2007.12.007

26. Bayry J, Lacroix-Desmazes S, Hermine O, Oksenhendler E, Kazatchkine MD, Kaveri SV. Amelioration of differentiation of dendritic cells from CVID patients by intravenous immunoglobulin. Am J Med (2005) 118(12):1439-40. doi:10.1016/j.amjmed.2005.06.028

27. Paquin-Proulx D, Santos BA, Carvalho KI, Toledo-Barros M, Barreto de Oliveira AK, Kokron CM, et al. IVIg immune reconstitution treatment alleviates the state of persistent immune activation and suppressed CD4 T cell counts in CVID. PLoS One (2013) 8(10):e75199. doi:10.1371/journal. pone.0075199

28. Smed-Sörensen A, Moll M, Cheng TY, Loré K, Norlin AC, Perbeck L, et al. IgG regulates the $\mathrm{CD} 1$ expression profile and lipid antigen-presenting function in human dendritic cells via FcgammaRIIa. Blood (2008) 111(10):5037-46. doi:10.1182/blood-2007-07-099549

29. Paquin-Proulx D, Santos BA, Carvalho KI, Toledo-Barros M, Oliveira AK, Kokron CM, et al. Dysregulated CD1 profile in myeloid dendritic cells in CVID is normalized by IVIg treatment. Blood (2013) 121(24):4963-4. doi:10.1182/blood-2013-04-499442

30. Bayry J, Lacroix-Desmazes S, Donkova-Petrini V, Carbonneil C, Misra N, Lepelletier Y, et al. Natural antibodies sustain differentiation and maturation 
of human dendritic cells. Proc Natl Acad Sci U S A (2004) 101(39):14210-5. doi:10.1073/pnas.0402183101

31. Wehr C, Kivioja T, Schmitt C, Ferry B, Witte T, Eren E, et al. The EUROclass trial: defining subgroups in common variable immunodeficiency. Blood (2008) 111:77-85. doi:10.1182/blood-2007-06-091744

32. Chapel H, Lucas M, Lee M, Bjorkander J, Webster D, Grimbacher B, et al. Common variable immunodeficiency disorders: division into distinct clinical phenotypes. Blood (2008) 112:277-86. doi:10.1182/blood2007-11-124545

33. Foerster C, Voelxen N, Rakhmanov M, Keller B, Gutenberger S, Goldacker S, et al. B cell receptor-mediated calcium signaling is impaired in B lymphocytes of type Ia patients with common variable immunodeficiency. JImmunol (2010) 184:7305-13. doi:10.4049/jimmunol.1000434

34. Yu JE, Knight AK, Radigan L, Marron TU, Zhang L, Sanchez-Ramon S, et al. Toll-like receptor 7 and 9 defects in common variable immunodeficiency. J Allergy Clin Immunol (2009) 124:349-56. doi:10.1016/j.jaci.2009.05.019

35. Tha-In T, Bayry J, Metselaar HJ, Kaveri SV, Kwekkeboom J. Modulation of the cellular immune system by intravenous immunoglobulin. Trends Immunol (2008) 29(12):608-15. doi:10.1016/j.it.2008.08.004

36. Heidt S, Roelen DL, Eijsink C, Eikmans M, Claas FH, Mulder A. Intravenous immunoglobulin preparations have no direct effect on B cell proliferation and immunoglobulin production. Clin Exp Immunol (2009) 158(1):99-105. doi:10.1111/j.1365-2249.2009.03996.x

37. Maddur MS, Hegde P, Sharma M, Kaveri SV, Bayry J. B cells are resistant to immunomodulation by 'IVIg-educated' dendritic cells. Autoimmun Rev (2011) 11(2):154-6. doi:10.1016/j.autrev.2011.08.004

38. Séité JF, Cornec D, Renaudineau Y, Youinou P, Mageed RA, Hillion S. IVIg modulates BCR signaling through CD22 and promotes apoptosis in mature human B lymphocytes. Blood (2010) 116:1698-704. doi:10.1182/ blood-2009-12-261461

39. Séité JF, Goutsmedt C, Youinou P, Pers JO, Hillion S. Intravenous immunoglobulin induces a functional silencing program similar to anergy in human B cells. J Allergy Clin Immunol (2014) 133(1):181-8.e1-9. doi:10.1016/j. jaci.2013.08.042

40. Bayry J, Fournier EM, Maddur MS, Vani J, Wootla B, Sibéril S, et al. Intravenous immunoglobulin induces proliferation and immunoglobulin synthesis from B cells of patients with common variable immunodeficiency: a mechanism underlying the beneficial effect of IVIg in primary immunodeficiencies. J Autoimmun (2011) 36(1):9-15. doi:10.1016/j.jaut.2010.09.006

41. Rui L, Vinuesa CG, Blasioli J, Goodnow CC. Resistance to CpG DNA-induced autoimmunity through tolerogenic B cell antigen receptor ERK signaling. Nat Immunol (2003) 4:594-600. doi:10.1038/ni924

42. Rakhmanov M, Keller B, Gutenberger S, Foerster C, Hoenig M, Driessen G, et al. Circulating CD21low B cells in common variable immunodeficiency resemble tissue homing, innate-like B cells. Proc Natl Acad Sci U S A (2009) 106(32):13451-6. doi:10.1073/pnas.0901984106

43. Visentini M, Cagliuso M, Conti V, Carbonari M, Mancaniello D, Cibati M, et al. Telomere-dependent replicative senescence of $\mathrm{B}$ and $\mathrm{T}$ cells from patients with type 1a common variable immunodeficiency. Eur J Immunol (2011) 41(3):854-62. doi:10.1002/eji.201040862

44. Visentini M, Marrapodi R, Conti V, Mitrevski M, Camponeschi A, Lazzeri C, et al. Dysregulated extracellular signal-regulated kinase signaling associated with impaired B-cell receptor endocytosis in patients with common variable immunodeficiency. J Allergy Clin Immunol (2014) 134(2):401-10. doi:10.1016/j.jaci.2014.03.017
45. Mitrevski M, Marrapodi R, Camponeschi A, Lazzeri C, Todi L, Quinti I, et al. Intravenous immunoglobulin replacement therapy in common variable immunodeficiency induces B cell depletion through differentiation into apoptosis-prone CD21(low) B cells. Immunol Res (2014) 60(2-3):330-8. doi:10.1007/s12026-014-8599-8

46. Bonilla FA, Barlan I, Chapel H, Costa-Carvalho BT, Cunningham-Rundles C, de la Morena MT, et al. International Consensus Document (ICON): common variable immunodeficiency disorders. J Allergy Clin Immunol Pract (2016) 4(1):38-59. doi:10.1016/j.jaip.2015.07.025

47. Malphettes M, Gerard L, Carmagnat M, Mouillot G, Vince N, Boutboul D, et al. Late-onset combined immune deficiency: a subset of common variable immunodeficiency with severe T cell defect. Clin Infect Dis (2009) 49(9):1329-38. doi:10.1086/606059

48. Paquin-Proulx D, Sandberg JK. Persistent immune activation in CVID and the role of IVIg in its suppression. Front Immunol (2014) 5:637. doi:10.3389/ fimmu.2014.00637

49. Issekutz AC, Rowter D, Miescher S, Käsermann F. Intravenous IgG (IVIG) and subcutaneous IgG (SCIG) preparations have comparable inhibitory effect on $\mathrm{T}$ cell activation, which is not dependent on IgG sialylation, monocytes or B cells. Clin Immunol (2015) 160(2):123-32. doi:10.1016/j.clim.2015.05.003

50. Melo KM, Carvalho KI, Bruno FR, Ndhlovu LC, Ballan WM, Nixon DF, et al. A decreased frequency of regulatory $\mathrm{T}$ cells in patients with common variable immunodeficiency. PLoS One (2009) 4(7):e6269. doi:10.1371/journal. pone. 0006269

51. Kasztalska K, Ciebiada M, Cebula-Obrzut B, Górski P. Intravenous immunoglobulin replacement therapy in the treatment of patients with common variable immunodeficiency disease: an open-label prospective study. Clin Drug Investig (2011) 31(5):299-307. doi:10.2165/11586710-00000000000000

52. Fulcher DA, Avery DT, Fewings NL, Berglund LJ, Wong S, Riminton DS, et al. Invariant natural killer (iNK) T cell deficiency in patients with common variable immunodeficiency. Clin Exp Immunol (2009) 157(3):365-9. doi:10.1111/j.1365-2249.2009.03973.x

53. MacMillan HF, Lee T, Issekutz AC. Intravenous immunoglobulin G-mediated inhibition of T-cell proliferation reflects an endogenous mechanism by which IgG modulates T-cell activation. Clin Immunol (2009) 132(2):222-33. doi:10.1016/j.clim.2009.04.002

54. Maddur MS, Vani J, Hegde P, Lacroix-Desmazes S, Kaveri SV, Bayry J. Inhibition of differentiation, amplification, and function of human Th17 cells by intravenous immunoglobulin. J Allergy Clin Immunol (2011) 127:823-30. doi:10.1016/j.jaci.2010.12.1102

55. Blausen.com staff. Medical gallery of Blausen Medical 2014. Wiki J Med (2014) 1(2):1-79. doi:10.15347/wjm/2014.010

Conflict of Interest Statement: IQ received travel grant, grant for Advisory Board participation and research grant from Kedrion, Shire, Octapharma, Grifols, and CSL Behring. MM declares no conflict of interest.

Copyright (c) 2017 Quinti and Mitrevski. This is an open-access article distributed under the terms of the Creative Commons Attribution License (CC BY). The use, distribution or reproduction in other forums is permitted, provided the original author(s) or licensor are credited and that the original publication in this journal is cited, in accordance with accepted academic practice. No use, distribution or reproduction is permitted which does not comply with these terms. 